\title{
Bases políticas das transferências intergovernamentais no Brasil (1985-2004)
}

\author{
OCTAVIO AMORIM NETO \\ ANDREI GOMES SIMONASSI*
}

\begin{abstract}
(2)
The politics of intergovernmental transfers in Brazil. This article examines the political economy of public resources distribution in Brazil's federal system in 1985-2004. We propose an empirical exercise to analyze how the country's federal governments deal with the tradeoff between the provision of material wellbeing to sub-national governments (the states in our study) and the pursuit of political support from the latter. To identify the determinants of the transfer of resources from the federal government to the states, a set of economic, political, and institutional variables is econometrically tested. Based upon instrumental variables estimation for panel-data models, our estimates indicate that in Brazil the pursuit of political goals prevails over social equity and economic efficiency criteria: higher levels of per capita transfers are associated with the political makeup of governing coalitions, while larger investments in infrastructure and development by the states are associated with a lower amount of per capita resources transferred to sub-national governments. Our findings also suggest a trend toward the freezing of interregional inequalities in Brazil, and show the relevance of fiscal discipline laws in discouraging the use of the administrative apparatus for electioneering.

Keywords: political economy; intergovernmental transfers; federalism; Brazilian state governments.

JEL Classification: H7; H77; P16; P35.
\end{abstract}

A grande maioria dos trabalhos de economia política do gasto público tem como preocupação central identificar as motivações subjacentes à alocação de

\footnotetext{
* Professor de Ciência Política da Escola Brasileira de Administração Pública e de Empresas da Fundação Getulio Vargas, EBAPE/FGV-Rio. E-mail: oamorim@fgv.br; Professor do Curso de Pós-Graduação em Economia da Universidade Federal do Ceará (CAEN/UFC). E-mail: agsimonassi@ufc.br. Os autores agradecem aos pareceristas da REP os excelentes comentários e ao professor George Avelino, da EASPFGV, as sugestões e informações fornecidas. Submetido: 3/julho/2012; Aprovado: 9/janeiro/2013.
} 
verbas governamentais. Essas motivações podem ser divididas em duas categorias: motivações políticas ou motivações voltadas para a promoção da eficiência econômica e da equidade social. Qual o peso que cada uma delas tem em um ou mais países ou em cada tipo de gasto? Eis o problema-chave, teórico e empírico, da literatura acadêmica sobre $\mathrm{o}$ assunto.

Os problemas relacionados à distribuição dos recursos públicos, especialmente no contexto de federações como a brasileira, têm sido discutidos tanto por economistas como por cientistas políticos. Alguns artigos, como o de Falleti (2005), além de tentar dar conta do problema-chave, procura também examinar a escolha do desenho institucional mais adequado para um país. Por exemplo, a insatisfação do eleitorado com a capacidade do governo central de equalizar a crescente demanda por bens e serviços públicos com suas respectivas ofertas tem sido justificativa para a adoção de uma forma descentralizada de organização do Estado. O benefício advindo da descentralização seria uma maior aproximação entre o governo e a população em termos de provimento das necessidades locais, reduzindo os custos de informação e favorecendo alocações mais eficientes, uma vez que permitiria identificar, de forma mais precisa e menos dispendiosa, as preferências dos cidadãos.

Argumento oposto àquele oferece o seguinte raciocínio: a descentralização, além de prejudicar a transparência institucional, exacerba as divergências existentes nas relações fiscais entre as distintas esferas de governo em consequência do "cobertor curto" que se observa entre as exigências da coordenação política e o esforço de redução da assimetria de informações acerca das preferências locais. Se, por um lado, a descentralização reduz a distância informacional entre o governo e a sociedade, por outro, o governo central perde controle sobre as administrações locais em decorrência da maior autonomia proporcionada a estas. Por exemplo, Ter-Minassian (1999) oferece evidências segundo as quais, em períodos de instabilidade econômica e política, como os verificados nas últimas duas décadas na Argentina e no México, esta falta de sintonia entre as esferas de governo agrava os desequilíbrios fiscais, comprometendo seriamente a estabilidade macroeconômica.

Convém registrar ainda que, na América Latina, o federalismo - ou a descentralização - acaba necessariamente interagindo com a dinâmica do presidencialismo, tipo de Executivo adotado por todos os países da região. No caso específico do Brasil, este sistema de governo funciona, na prática, como um presidencialismo de coalizão (Abranches, 1988), sob o qual o chefe de Estado, apesar de suas extensas prerrogativas constitucionais, se vê obrigado, em virtude da fragmentação do Congresso, a negociar um acordo interpartidário para formar uma maioria legislativa, sem a qual a efetividade do governo, ou mesmo a sobrevivência do presidente no cargo, é seriamente ameaçada. Assim, a interação entre as exigências do presidencialismo de coalizão e a perda de capacidade de coordenação política decorrente do aprofundamento da descentralização determinado pela Constituição de 1988 exerceu forte influência sobre o processo de decisão dos gastos públicos. Como resultado, o federalismo fiscal praticado no país passou a constituir um intenso processo de barganha política-constitucional, tanto entre o governo central e os governos subnacionais, como dentro de cada esfera de governo (Abrucio, 1998; Abrucio \& Costa, 1999).

Dentre os estudos nacionais e internacionais que incorporam com maior precisão a conexão entre os fatores políticos e a alocação dos recursos públicos, destacam- 
-se os trabalhos de Cossio (2000), Souza (2003), Gibson, Calvo e Falleti (2004) e Arretche e Rodden (2004), a serem resenhados na próxima seção, os quais mostram haver intensas relações entre, de um lado, regimes políticos, sistemas eleitorais, ideologias políticas e ciclos eleitorais, e, de outro, o crescimento dos gastos ou a sua composição. Porém, dado que tais gastos crescem de diferentes formas e por diferentes causas em cada país, estudos de casos nacionais se fazem necessários para que se possa identificar com mais acuidade os fatores políticos específicos da economia política do gasto público. Com esta finalidade, este trabalho almeja ampliar as contribuições anteriores, investigando empiricamente até que ponto no Brasil, entre 1985 e 2004, necessidades políticas determinam a alocação dos recursos públicos. Note-se que, caso as necessidades políticas prevaleçam sobre as socioeconômicas, a consequência imediata pode ser o aumento dos desequilíbrios fiscais, com o agravamento das desigualdades inter-regionais. Ao adotar uma abordagem empírica com métodos estatísticos, este estudo distancia-se de outros mais teóricos, como o de Souza (2003), aproximando-se, assim, de trabalhos como o de Arretche e Rodden (2004).

A hipótese central aqui considerada afirma serem as transferências intergovernamentais de recursos um importante mecanismo utilizado pelo Executivo federal para a consecução de objetivos políticos e, portanto, a causa primordial do caráter realocativo do federalismo fiscal brasileiro sugerido pela literatura. ${ }^{1}$ Para verificar tal hipótese, este artigo se organiza em cinco seções, além desta introdução. Para reforçar os argumentos já apresentados, a segunda seção apresenta uma revisão da literatura relacionada à economia política das transferências intergovernamentais; a terceira seção concentra a análise no caso brasileiro, com ênfase no seu marco institucional, na evolução e nos determinantes políticos das transferências de recursos públicos no país, além de apresentar uma crítica à literatura sobre o tema. $\mathrm{Na}$ quarta seção desenvolve-se um modelo teórico e explica-se a técnica econométrica utilizada. Os resultados estatísticos se encontram na quinta seção. Finalmente, na última seção, são enunciadas as considerações finais.

\section{TRANSFERENNCIAS INTERGOVERNAMENTAIS NA AMÉRICA LATINA E NO BRASIL}

Gibson, Calvo e Falleti (2004) examinam o impacto das características institucionais sobre as políticas públicas nos sistemas federativos de países como a Argentina, o Brasil, o México e os Estados Unidos. A principal proposição desses autores sustenta haver um considerável efeito da excessiva representação política de alguns estados/províncias sobre a distribuição do gasto público. Operacionalmente, testa-se a hipótese segundo a qual unidades federativas com maior número de representantes nas casas legislativas seriam privilegiadas na alocação dos recur-

\footnotetext{
${ }^{1}$ O federalismo realocativo, segundo Gibson, Calvo e Falleti (2004), se caracteriza por um padrão desproporcional de alocação dos recursos públicos para alguns estados em virtude da grande influência político-econômica destes.
} 
sos públicos. A corroboração da referida hipótese implica a existência de um federalismo realocativo, verificado no Brasil e na Argentina, ao passo que a rejeição indica haver um federalismo proporcional, observado nos outros dois países. Os dados desses autores mostram que a sobrerrepresentação legislativa de alguns estados brasileiros e províncias argentinas estaria diretamente relacionada às estratégias adotadas pelo governo central para formar coalizões políticas, fato que, por sua vez, implica o aumento dos gastos discricionários para essas unidades federativas. $^{2}$

Em relação especificamente ao Brasil, destaque-se o artigo de Cossio (2000), o qual analisa o efeito de algumas variáveis políticas sobre a alocação de recursos públicos. A partir de modelos econométricos com dados em painel para o período 1985-1997, esse autor estima a influência das características dos subsistemas políticos estaduais sobre o comportamento fiscal destas unidades federativas. Quatro modelos para explicar a despesa primária per capita dos estados e a sua variação são propostos, constatando-se que: (i) existe influência da dinâmica política na política fiscal dos estados; (ii) há uma relação direta entre, de um lado, a fragmentação do sistema partidário estadual e o comparecimento eleitoral, e, de outro, a política fiscal dos estados; e (iii) não se pode inferir que a orientação ideológica ou a afinidade com a orientação ideológica do governo central possui papel relevante para explicar o comportamento da despesa primária estadual.

Mais recentemente, Arretche e Rodden (2004) procuraram estimar a influência das estratégias eleitorais e legislativas do governo central na distribuição das transferências intergovernamentais. Esses autores avaliam tanto hipóteses que tratam as transferências como um instrumento para obtenção de votos quanto a estratégia utilizada pelo presidente para angariar apoio parlamentar. A análise empírica, com dados desagregados por estado, tem como intuito específico verificar os fatores que influenciam as transferências correntes, as transferências não constitucionais ou voluntárias, e as transferências do FGTS, em três períodos (1991-2000, 1996-2000 e 1997-2000). O referido estudo conclui que os presidentes brasileiros utilizam essas rubricas de gastos sobretudo como um instrumento de obtenção de apoio parlamentar, refutando, porém, a hipótese segundo a qual os governadores pertencentes à coalizão ou partido presidencial seriam beneficiados na distribuição desses recursos.

Este artigo procura contribuir com o debate acadêmico brasileiro em pelo menos dois aspectos: (i) em relação ao artigo de Cossio (2000), analisa as transferências e não o resultado primário ou o gasto público agregado; e (ii) em relação ao trabalho de Arretche e Rodden (2004), contribui para o conhecimento cumulativo a respeito dos determinantes político-econômicos dos recursos transferidos aos estados brasileiros. Além disso, convém registrar que a escolha da variável dependente é coerente com a constatação de Arretche (2005), segundo quem as disputas fede-

\footnotetext{
${ }^{2}$ Gastos cuja finalidade é satisfazer interesses políticos.
} 
rativas no Brasil, desde a promulgação da Carta de 1988, passaram das discussões sobre a tributação exclusiva para os debates a respeito das transferências fiscais.

Isso posto, cabe, antes de tudo, averiguar o que a evidência empírica relativa à evolução das transferências de recursos no Brasil indica. Ou seja, antes de detalhar a estratégia analítica deste artigo, é necessário investigar o marco institucional que regula as transferências intergovernamentais e o padrão de comportamento dos recursos públicos destinados aos governos estaduais.

\section{FEDERALISMO FISCAL: O CASO BRASILEIRO}

\section{O Marco Institucional das Transferências Intergovernamentais}

O mecanismo de transferências de receitas tem a finalidade de promover o equilíbrio financeiro adequado aos diversos níveis de governo, bem como possibilitar ações intergovernamentais conjuntas. Procura-se, por meio desse mecanismo, dotar os governos subnacionais de recursos adicionais aos de suas competências tributárias, de modo a viabilizar a sua manutenção e o provimento dos serviços públicos a eles vinculados.

Vale ressaltar que questionar o caráter centralizador ou descentralizador do federalismo brasileiro não é objetivo central deste estudo. Arretche (2009, p. 380) mostra que, após a promulgação da Carta de 1988, o país passou a ter "um modelo de Estado federativo que combina ampla autoridade jurisdicional à União com limitadas oportunidades institucionais de veto aos governos subnacionais". Assim, cabe investigar como e por meio de que critérios essa poderosa União transfere recursos às unidades subnacionais.

A partir da promulgação da Constituição de 1988, é possível dividir as transferências de recursos em dois grupos conforme a natureza jurídica da transferência: transferências constitucionais e transferências voluntárias. No primeiro grupo, estão as expressamente previstas na Carta Magna, as quais obrigam os entes federados a repasses parciais de alguns tributos, como o Imposto de Renda (IR) e o Imposto sobre Produtos Industrializados (IPI), arrecadados pelo governo federal e transferidos aos estados e municípios por meio dos seus respectivos fundos de participação, ${ }^{3}$ do Fundo Constitucional de Compensação pela Exportação de Produtos Industrializados e da Lei Complementar $\mathrm{n}^{\circ} 87 / 96 .{ }^{4} \mathrm{O}$ segundo compreende os recursos financeiros repassados pela União aos estados, ao Distrito Federal e aos municípios em decorrência de acordos, convênios, ajustes ou outros instrumentos

\footnotetext{
${ }^{3}$ No plano estadual, que é o foco deste estudo, o Fundo de Participação dos Estados (FPE) é composto de $21,5 \%$ do IR e do IPI, sendo determinado de acordo com critérios como população e área geográfica, dentre outros fatores.

${ }^{4}$ Também conhecida como Lei Kandir. Esta tem por objetivo compensar as perdas geradas pelo Imposto sobre Circulação de Mercadorias e Serviços (ICMS), imposto estadual.
} 
similares cuja finalidade seja a realização de obras e/ou serviços de interesse comum às três esferas de governo. Nos termos da Lei de Responsabilidade Fiscal (LRF), uma transferência voluntária seria uma "entrega de recursos correntes ou de capital a outro ente da Federação, a título de cooperação, auxílio ou assistência financeira, que não decorra de determinação constitucional, legal ou destinada ao Sistema Único de Saúde (SUS)".

Há um consenso na literatura segundo o qual as transferências fiscais intergovernamentais possuem características marcantes das finanças públicas de cada país e, dados os conceitos apresentados, seria, então, natural que o nível apropriado de transferências entre as esferas de governos fosse determinado por noções de eficiência e equidade. Entretanto, ao se avaliar a estrutura dos modelos de transferências de recursos, é indispensável atentar para os incentivos que elas geram aos governos locais e aos residentes das diferentes regiões do país. Faz-se mister, em primeiro lugar, reconhecer a natureza política das transferências. Por exemplo, pode ser necessário deixar de transferir recursos a determinadas localidades que precisem deles intensamente, de modo a viabilizar recursos para outras que sejam mais relevantes politicamente. Concomitantemente, supor um colateral visando à consecução dos objetivos políticos consiste em uma ameaça ao equilíbrio financeiro das economias nacionais. Este é um novo ponto de discussão da literatura atual.

No caso do Brasil, uma federação altamente heterogênea, é, de certa forma, natural que questões e interesses políticos governem a trajetória dos gastos públicos, no caso, as transferências de recursos, em detrimento de aspectos relacionados a necessidades econômicas efetivas. Quando isso ocorre, de acordo com Gibson, Calvo e Falleti (2004), o federalismo realocativo prepondera sobre o proporcional. O problema surge quando a influência dos objetivos políticos sobre as decisões de gastos passa a agravar as desigualdades regionais e/ou a comprometer a ética de responsabilidade fiscal.

Dessa forma, outra hipótese considerada neste artigo afirma que tanto as transferências discricionárias como as cuja única finalidade seja o financiamento de déficits são invariavelmente ruins. Ao mesmo tempo, a alocação de recursos visando exclusivamente à melhoria da infraestrutura das economias locais, por exemplo, gera impactos apenas no longo prazo, enfraquecendo, consequentemente, o incentivo que tem o governo central para efetuar tais alocações. A fim de explicitar como o governo central lida com este "cobertor curto", é importante analisar o padrão de comportamento das transferências de recursos entre as esferas de governo no Brasil, bem como verificar a significância das variáveis econômicas que indicariam algum caráter redistributivo no federalismo brasileiro.

\section{Os determinantes econômicos e políticos da alocação de recursos públicos no Brasil}

Esta seção apresenta uma discussão acerca dos fatores que determinam a alocação dos recursos públicos no Brasil à luz das teorias apresentadas na segunda 
seção, de modo a justificar o exercício empírico cujos resultados serão apresentados na quinta seção.

Para estabelecer a variável a ser explicada neste estudo, convém notar que Arretche e Rodden (2004) desagregam as transferências em constitucionais e voluntárias. Entretanto, verifica-se, empiricamente, que o montante das transferências discricionárias é pequeno em relação à rubrica que é majoritariamente prevista em lei. Não obstante, se essas transferências constitucionais são limitadas por dispositivos legais, analisar sua variação em relação à média de um período, ou ainda o seu crescimento, é um modo robusto para mensurar, por exemplo, o comportamento das transferências voluntárias. Desse modo, a investigação empírica deste artigo incidirá sobre o montante (nível medido em diferenças com relação a uma média no tempo) e a evolução (taxa de crescimento) do total per capita transferido aos estados, com dados deflacionados.

Em relação às variáveis explicativas, inicialmente desagregamos os instrumentos utilizados pelo governo central de acordo com o caráter destes na estratégia política a ser seguida. Independentemente da escolha entre priorizar aspectos de equidade ou a formação de coalizões políticas, as variáveis econômicas e políticas são os pilares de sustentação de um governo: o primeiro grupo de variáveis afeta a popularidade do governo, enquanto o segundo diz respeito ao relacionamento entre o governo e os atores políticos diretos (partidos e governadores).

\subsection{Variáveis Econômicas:}

i) Renda do eleitor (rendeleit): o primeiro ponto a ser investigado no estudo diz respeito à relação entre o destino das transferências do governo central e o tamanho econômico dos estados mais beneficiados. Nesse caso, o cerne da análise consiste em observar a evolução dos recursos distribuídos de acordo com a renda per capita da população e/ou do eleitorado. Arretche (2010) cita o papel regulador da União como causa de maior montante de recursos destinados à área de saúde nas economias mais pobres, mas a constatação segundo a qual a evolução das transferências de recursos per capita é mais acentuada nas regiões mais pobres nos permitirá inferir se a finalidade daquelas se dá por critérios de equidade ou se tais recursos contribuiriam para a manutenção das desigualdades inter-regionais.

ii) Gastos em infraestrutura: investimentos públicos em infraestrutura para o desenvolvimento regional podem influenciar as decisões dos governantes de duas formas: (i) se, por um lado, é consenso que todo político, durante as campanhas eleitorais, atribui grande valor a obras realizadas, ou até àquelas ainda em andamento, (ii) há um risco inerente à alocação de recursos nessa rubrica em virtude da possibilidade de que os prazos relativos à execução e oferta dos benefícios decorrentes de tais investimentos possam não ser cumpridos. Em muitos casos, se realizariam gastos que gerariam benefícios à população apenas no médio e longo prazos, e, dado o fosso entre a duração dos mandatos presidenciais no Brasil e o tempo necessário à concretização dos investimentos em infraestrutura, é possível inferir que os gastos nessa área não constituiriam objetivos políticos primordiais. Nos modelos econométricos propostos neste estudo, isso se traduziria na insignificância 
estatística ou em um sinal negativo da estimativa associada à variável de gastos relacionados à rubrica "infraestrutura". A elevação dos gastos dessa natureza teria, então, um impacto negativo sobre as transferências de recursos aos estados. Como? Supondo-se que uma das necessidades vitais do presidente é formar e manter coalizões governativas, tal elevação seria uma forma ineficiente de aplicar os recursos públicos. Todavia, se o objetivo é fazer uma redistribuição equitativa desses, espera-se um impacto positivo.

iii) Gastos com pessoal e LRF: quanto mais fiscalizados os administradores públicos, menores as chances de transferirem recursos aos seus aliados políticos por qualquer rubrica. Portanto, outro fator que viria a comprometer o fluxo de transferências aos estados seriam as Leis Complementares que propõem maior austeridade nas contas dos estados, a exemplo das Leis $\mathrm{n}^{\circ} 82,{ }^{5} \mathrm{n}^{\circ} 96^{6}$ e $\mathrm{n}^{\circ} 101^{7}$ que, dentre outros aspectos, limitam as despesas com pessoal em $60 \%$ da receita corrente líquida dos estados. Essa limitação impede, por exemplo, a contratação de funcionários em períodos eleitorais, prática que costumava ser um relevante instrumento de manipulação política.

\subsection{Variáveis políticas:}

Em relação aos determinantes políticos do montante de recursos transferidos aos estados, destacam-se variáveis relativas aos diversos níveis do sistema político que são decisivas no processo de barganha constitucional:

iv) Afinidade politica entre o governador e o presidente (govpres): note-se que se um dos objetivos primordiais do presidente é ter uma base de apoio parlamentar majoritária, a composição partidária e estadual da coalizão governativa montada pelo presidente deve ter uma relação direta com a evolução dos recursos transferidos aos estados, ou seja, o alinhamento político entre a União e um estado deve implicar mais recursos transferidos a este último. Mas como se dá esse alinhamento?

v e vi) Força dos estados nos ministérios (vministerial) e força política do presidente em cada estado (presnauf): a Constituição de 1998, assim como todas as outras Constituições republicanas que teve o país, confere ao chefe do Executivo amplos poderes sobre a administração pública. Um dos principais é o que dá ao presidente a faculdade de nomear e demitir livremente os ministros. Ainda que o presidente tenha tal faculdade, observa-se que a formação ministerial no Brasil tem duas dimensões fundamentais não determinadas pela Carta Magna: a partidária e a regional (Abranches, 1988; Amorim Neto, 2000, 2007; Figueiredo, 2008). A primeira diz respeito a como o presidente pretende se relacionar com os partidos representados no Congresso Nacional; a segunda, a como o chefe do Executivo tenciona lidar com as forças políticas das unidades da Federação. Ou seja, ainda

\footnotetext{
${ }^{5}$ Lei Camata I.

${ }^{6}$ Lei Camata II.

${ }^{7}$ Lei de Responsabilidade Fiscal (LRF).
} 
que o mandato do presidente seja fixo e independente da sobrevivência da legislatura, os presidentes brasileiros usam as nomeações ministeriais, de maneira relativamente semelhante à de um primeiro-ministro, como um dos principais recursos para construir a sua base de apoio no Poder Legislativo e na Federação. No que diz respeito ao Congresso Nacional, esse expediente é necessário em virtude da alta fragmentação legislativa verificada no país, a qual torna muito pouco frequente a existência de um partido presidencial majoritário nas duas Casas do Congresso. No que toca à Federação, o uso das nomeações ministeriais pelo presidente tem como objetivos principais atender às demandas dos governadores por influência em determinadas áreas da administração federal e premiar aliados nos estados. ${ }^{8}$

Ou seja, conquanto tenha amplas prerrogativas constitucionais para agir unilateralmente, o presidente brasileiro tem de conviver com um Congresso bicameral operado por um sistema partidário altamente fragmentado e fluido, e com uma Federação robusta, forçando o chefe do Executivo a montar complexas coalizões governativas, dando vez ao chamado presidencialismo de coalizão. ${ }^{9}$ Como já dito, as coalizões no Brasil têm uma dimensão partidária e uma dimensão estadual. No que toca à primeira, Amorim Neto (2007) mostra que aquelas são sempre arranjos multipartidários com maior ou menor grau de fragmentação, heterogeneidade ideológica, e extensão do apoio legislativo que conseguem gerar para o Executivo. ${ }^{10}$ Com relação à dimensão regional dos gabinetes presidenciais, o seu aspecto decisivo é a avaliação do peso que neles têm os estados. Portanto, do ponto de vista operacional, seguem-se aqui os critérios estipulados por Amorim Neto (2007) para definir quando a origem estadual de um ministro é relevante ou irrelevante para a sua nomeação. ${ }^{11}$ Esse autor identifica também uma considerável variação na composição estadual dos ministérios.

Qual é o significado da grande variação na composição partidária e estadual dos gabinetes presidenciais para o estudo dos critérios políticos que regem as transferências intergovernamentais? Tal variação pode gerar graus diversos de força política do presidente nos estados, graus diversos de convergência (ou divergência) partidária entre, de um lado, os governadores, e de outro, a coalizão governativa do presidente, e pesos diversos dos estados na coalizão governativa do presidente. Dito de outra maneira, o

\footnotetext{
${ }^{8}$ Convém notar que há uma controvérsia acadêmica em torno do impacto dos governadores sobre o comportamento legislativo no plano nacional. Enquanto Carey e Reinhardt (2003) sustentam que os governadores reduzem a disciplina legislativa das coalizões partidárias com as quais estão associados, Cheibub, Figueiredo e Limongi (2009) afirmam que tal impacto inexiste e que o comportamento legislativo dos parlamentares (tomados individualmente) e das bancadas estaduais representadas na Câmara é determinado por forças nacionais. Independentemente da posição que se tome em relação a esse debate, é incontroverso o fato de terem os governadores influência sobre um número considerável das nomeações ministeriais.

${ }^{9}$ Para uma ampla resenha crítica da literatura sobre o presidencialismo de coalizão, ver Power (2010).

${ }^{10}$ Dados para todos os gabinetes formados em 1985-2006 se encontram em Amorim Neto (2007).

${ }^{11}$ Amorim Neto (2007) apresenta dados com o percentual de nomeações ministeriais controlado pelos estados por presidência, entre 1985 e 2006.
} 
alinhamento do estado com a coalizão do presidente se dá mais pela via das nomeações ministeriais do que pela simples coincidência partidária entre o presidente e o governador. Nesse sentido, é natural que quanto maior a força política do presidente nos estados, mais beneficiados devam ser estes em relação ao montante de recursos transferidos. Espera-se também que quanto maior o peso político de um estado, maior o volume de recursos que lhe são transferidos, peso medido seja pela percentagem de legisladores que um estado tem na coalizão governativa, seja pela percentagem de ministérios ocupados, seja pelo tempo de ocupação dos postos ministeriais. Entretanto, deve ser ressaltado o caráter endógeno dessas duas últimas medidas, fato que exige a aplicação de procedimentos estatísticos adequados, ${ }^{12}$ de forma a não enviesar a análise dos resultados obtidos no exercício empírico a ser feito. Cabe ainda ressaltar que a instabilidade política do período 1985-1994 reduziu sobremaneira o tempo médio dos ministros em suas pastas, fato que, por sua, vez compromete uma análise consistente do tempo ministerial de cada estado neste período. Desse modo, será considerado o efeito desta variável apenas no período 1995-2004.

\section{ASPECTOS METODOLÓGICOS}

Dada a motivação subjacente aos determinantes da alocação de recursos públicos identificados na terceira seção, adota-se aqui a proposta de Rao e Singh (2000), a qual considera o federalismo fiscal como sendo fundamentalmente caracterizado por um processo de barganha constitucional. Embora seja inviável a elaboração de um modelo que incorpore aspectos como a evolução e a influência da estrutura institucional sobre a alocação dos recursos públicos, representar-se-á o federalismo fiscal brasileiro como um jogo entre agentes políticos: o presidente, os governadores e os parlamentares.

Assim como em Rao e Singh (2000), considera-se aqui que as transferências intergovernamentais constituem o canal para a distribuição do bônus advindo da federação e, portanto, as variáveis políticas e econômicas a serem examinadas serão utilizadas como medidas indiretas (em inglês, proxies) e/ou determinantes do poder de barganha de cada ator. De maneira complementar, a análise empírica a ser feita segue a proposta de Berry e Lowery (1987), a qual recomenda a desagregação da variável relativa ao gasto público para superar as limitações teóricas das explicações tradicionais oferecidas desde a década de 1970. Segundo esses autores, a razão principal para desagregar a variável dependente diz respeito ao fato de que:

existem diversas explicações para o crescimento do governo nos EUA, todavia, elas não apresentam consistência [...] e uma das razões para tal inconsistência se deve ao fato de que a variável explicada - o tamanho total do governo - está sendo considerada em elevado grau de agregação [...] desagregando a variável dependente, estamos estabelecendo uma

\footnotetext{
${ }^{12}$ Para contornar este problema, será utilizado o método de variáveis instrumentais.
} 
divisão clara entre dois tipos diferentes de gastos públicos. Uma parte dos gastos são as transferências [...] e o restante compreende a aquisição de bens e serviços, em que o governo atua adquirindo recursos (capital e trabalho) que serão utilizados na produção das políticas públicas. (Berry e Lowery, 1987, pp. 401-405)

Assim, este artigo adota a desagregação da variável relativa ao gasto público. Conforme será detalhado adiante, o foco do estudo incidirá sobre a rubrica de transferências correntes por habitante e medida como variação em relação a uma média temporal, em termos reais, feitas pelo governo central para os estados e em sua taxa de crescimento.

Tal qual no trabalho de Arretche e Rodden (2004), modelos econométricos com dados em painel serão aqui utilizados em uma análise empírica para dar robustez às respostas às questões levantadas nesta seção, bem como para evidenciar como o governo lida com o "cobertor curto" apresentado ao final da seção seguinte. Convém registrar que a técnica econométrica adotada neste artigo e as variáveis explicativas apresentadas nesta seção constituem avanços em relação aos estudos sobre o Brasil.

\section{Dados e hipóteses}

O restante deste trabalho investiga a validade das teorias apresentadas na seção anterior, testando algumas hipóteses discutidas. Desse modo, almeja-se ampliar as propostas anteriores de Arretche e Rodden (2004) e Cossio (2000), tanto no que toca ao horizonte temporal, como em termos da técnica de estimação utilizada.

Dados da Secretaria do Tesouro Nacional para as finanças públicas estaduais e informações políticas divulgadas pelos Tribunais Regionais Eleitorais foram utilizados na elaboração de variáveis testadas em uma análise em painel para 24 estados brasileiros no período 1985-2004. Tocantins, Roraima e Distrito Federal não foram incluídos na análise devido à indisponibilidade de informações para alguns períodos. Desse modo, a base de dados utilizada compreende: (i) gastos estaduais em infraestrutura (dinfr) e renda do eleitorado (rendaeleit); (ii) as rubricas necessárias à construção do índice de gastos com pessoal previsto nas Leis Camata I e II e na LRF (ilrf); e (iii) as variáveis políticas apresentadas (govpres, presnauf e vministerial).

Diferentemente de Cossio (2000), cujo foco de análise consiste no montante do gasto público federal, e consoante os argumentos apresentados, adota-se como variável dependente o nível e o logaritmo do total de transferências intergovernamentais per capita feitas pelo governo federal aos estados em termos reais, utilizando como deflator o Índice Geral de Preços (IGP-DI) da Fundação Getulio Vargas.

Reforçando os argumentos apresentados, a primeira variável econômica utilizada no modelo empírico é a proporção dos gastos estaduais em infraestrutura. Nesse caso, existem as duas possibilidades já discutidas. Todavia, conquanto se reconheça o apelo político das áreas sociais, se o objetivo do presidente é conquistar eleitores, ao invés de solidificar coalizões legislativas, a evolução dos recursos per 
capita destinados aos estados deveria ter relação direta com a proporção do orçamento destes destinada à área de infraestrutura, pois seria um indicativo de ser o crescimento econômico o objetivo do governo central, objetivo que não seria comprometido pelas necessidades políticas do presidente.

Note-se que, em uma economia escassa de recursos, muitas vezes a consecução dos objetivos políticos não entra em sintonia com a promoção do crescimento econômico. Em especial nos estados de regiões mais pobres, a demanda por recursos supera a oferta destes, sendo preciso decidir as rubricas prioritárias para sua alocação.

Uma segunda hipótese, já discutida, diz respeito aos impactos das Leis Complementares que objetivaram disciplinar os gastos públicos no Brasil. Em termos de gastos com pessoal, as Leis Camata I e II e a Lei de Responsabilidade Fiscal preveem os mesmos limites: até $60 \%$ da Receita Corrente Líquida ${ }^{13}$ dos estados. Desse modo, não há perda de generalidade ao utilizar-se o índice calculado de acordo com esses três dispositivos como variável explicativa do montante de recursos per capita transferido aos estados no período 1985-2004. Entretanto, a decisão de incluir essa nova variável está condicionada à escolha de uma técnica de estimação adequada, no sentido de se calcular corretamente os parâmetros do modelo proposto, considerando-se a possibilidade de endogeneidade dos regressores utilizados.

Em relação às variáveis políticas, a partir da discussão feita, quatro variáveis foram selecionadas de acordo com: (i) a força política da coalizão do presidente nos estados (presnauf); (ii) a relação partidária entre presidente e governador (govpres); (iii) o tempo ministerial usado pelos estados por ano (vministerial); e (iv) os períodos eleitorais (elei).

Os sinais esperados para os coeficientes estimados seguem os argumentos: se o objetivo primordial do presidente é formar e manter coalizões governativas, ele deve alocar seus recursos de acordo com o peso dos estados no seu governo e com a força política da sua coalizão nos estados. A relação direta se verificaria, então, tanto no nível como no crescimento desses recursos. Já a simples coincidência partidária entre governador e presidente, conforme discutido, não é garantia de uma alocação eficiente ${ }^{14}$ dos recursos recebidos.

Dadas a relevância da política estadual no plano nacional e a instabilidade política verificada entre 1985 e 1994, a análise do impacto da participação ministerial dos estados sobre o montante de recursos per capita a estes destinados é realizada sob três perspectivas: para o período 1985-2004, nos 24 estados que constituem a amostra e apenas para os estados da região Sudeste; e para o período 1995-2004, em todos os estados incluídos na amostra.

\footnotetext{
13 Representa a soma das receitas próprias e de transferências dos estados, destas excluídas as transferências intergovernamentais.

${ }^{14}$ Eficiência, aqui, seria no sentido de que os recursos destinados aos estados devem ser alocados nas áreas definidas pelo presidente, fato que depende muito mais dos deputados e senadores que do governador.
} 


\section{Transformação das variáveis em diferentes especificações}

\section{A escolha da variável dependente}

Visando reforçar os critérios da escolha da variável dependente a ser utilizada neste estudo, os Gráficos 1 e 2 apresentam, respectivamente, a participação média das transferências voluntárias sobre o total de transferências correntes a cada estado e as correlações entre estas duas rubricas de transferências entre 1985 e 2004.

O Gráfico 1 demonstra que os critérios que regem constitucionalmente a distribuição de recursos da União aos estados faz com que a participação média das transferências voluntárias no total oscile entre $11,1 \%$ e $94,8 \%$ entre as unidades federativas. A prioridade dada aos estados do Nordeste $(52,46 \%)$ e Norte $(25,37 \%)$ na distribuição do Fundo de Participação dos Estados (FPE) é uma das causas dos diferentes percentuais no referido gráfico.

Gráfico 1: Participação Média das Transferências Voluntárias no Total de Transferências Correntes aos Estados Brasileiros

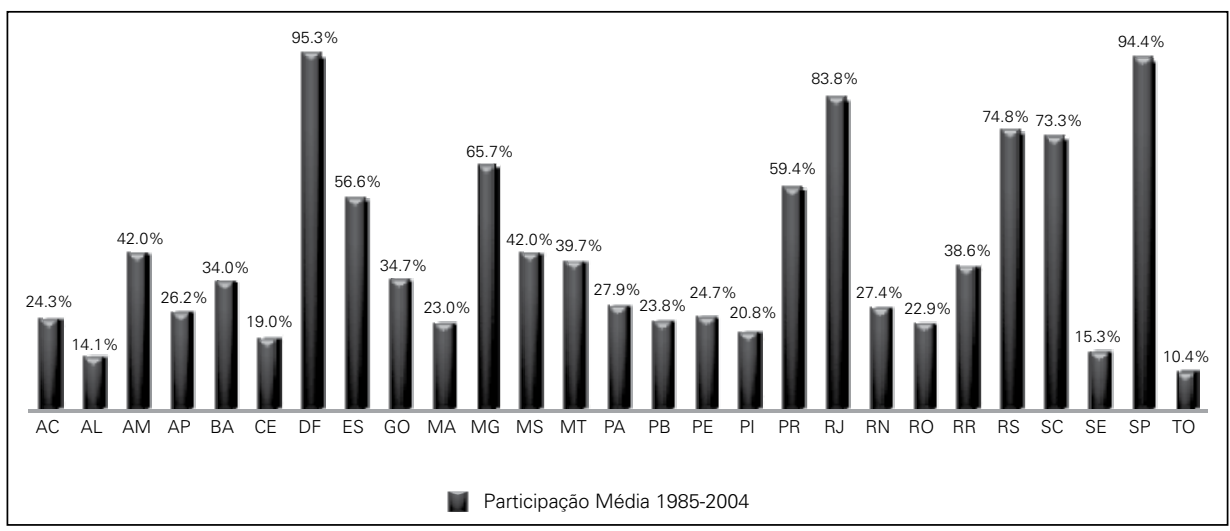

Fonte: Elaboração dos autores.

Por outro lado, os impactos de cada variável de controle sobre o montante transferido a cada estado em termos reais e per capita é o que interessa na análise feita neste estudo. Desse modo, cabe, no Gráfico 2, analisar os comovimentos entre o total de transferências correntes e voluntárias aos estados a fim de verificar se a escolha da variável dependente como o total de transferências correntes permite uma interpretação distinta da de estudos como o de Arretche e Rodden (2004), que utilizam apenas a componente de transferências voluntárias como objeto de investigação.

Observa-se que, à exceção do Amapá e de Alagoas, os comovimentos entre as duas rubricas são superiores a $90 \%$, e, mesmo nesses dois estados, a associação é bastante elevada. Além do Distrito Federal, em estados como Paraná, Rio Grande do Sul, Rio de Janeiro e São Paulo, por exemplo, a associação linear é perfeita. Comprova-se, portanto, que a inclusão das transferências constitucionais no cômputo da variável dependente, se não reforça, de forma alguma compromete o exercício empírico a ser realizado. 


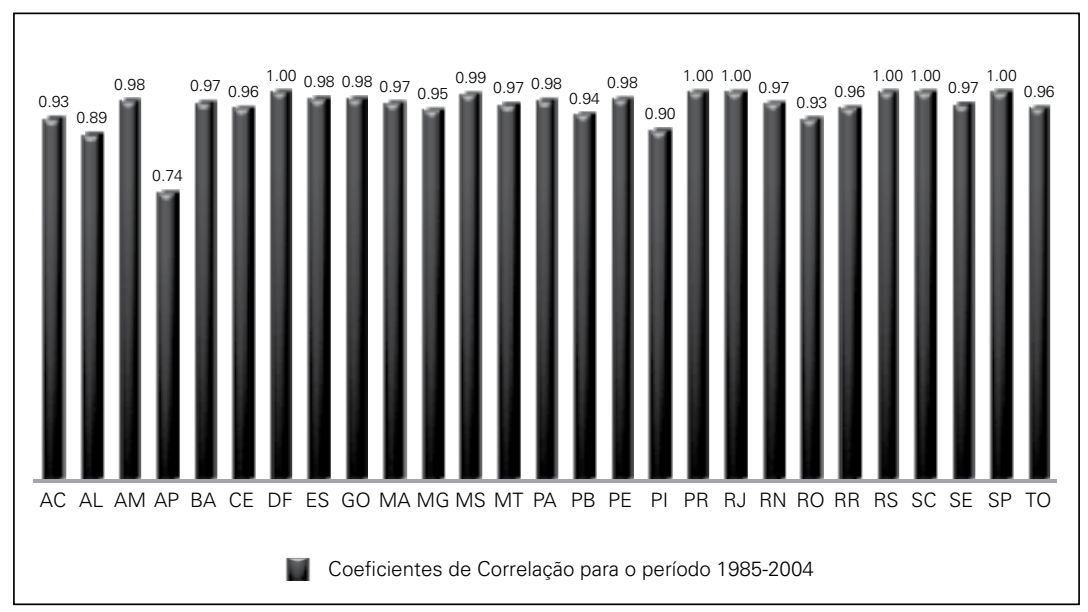

Fonte: Elaboração dos autores.

Não obstante, ressalte-se que, ao se estimar os parâmetros de um modelo com dados em painel por meio de uma estimação baseada em efeitos fixos, reespecifica-se o mesmo por meio da substituição das variáveis por seus desvios em relação às médias temporais. Como aqui se trabalha com transferências correntes deflacionadas e por habitante, na estimação por efeitos fixos, a interpretação correta de trpc no modelo, assim como de qualquer variável explicativa, será por meio da variação em relação à média do período 1985-2004. Em outras palavras, o que está sendo explicado é a variação temporal das transferências por habitante em relação a uma variação temporal de cada determinante no processo de barganha constitucional.

Tudo o que é fixo temporalmente em termos reais e per capita é eliminado na estimação por efeitos fixos e parcialmente eliminado na estimação por efeitos aleatórios. Desse modo, o que se analisa é exatamente o impacto sobre o que é "atípico" em termos de transferências aos estados. A hipótese subjacente afirma que este montante é uma boa referência para mensurar privilégios na distribuição de recursos e que o registro como transferência voluntária pode muitas vezes ser evitado no processo de alocação de recursos. Mais especificamente, se o montante de transferências constitucionais, em termos reais, fosse mantido anualmente, toda a parcela advinda de dispositivos legais é eliminada e o que resta são apenas os aumentos da parcela constitucional acima da inflação e transferências discricionárias e/ou voluntárias.

No tocante à variável relativa às transferências per capita em termos reais em logaritmo, de forma análoga à estimação por efeitos fixos, identifica-se a influência de oscilações temporais nas variáveis escolhidas sobre oscilações temporais no crescimento do montante de recursos por habitante transferido. Assim, um impacto positivo implica uma elevação do que foi transferido, devendo tal elevação ser superior à média verificada no período amostral analisado. 


\section{O modelo econométrico}

Formalmente, dois modelos gerais resumem a análise empírica realizada neste estudo:

$$
\begin{aligned}
& \operatorname{trpc}_{\text {itt }}=\beta_{\text {oit }}+\beta_{1} \text { presnauf }_{\text {it }}+\beta_{2} \text { govpres }_{\text {it }}+\beta_{3} \text { dinfr }_{\text {it }}+\beta_{4} \text { ilrf }_{\text {it }}+\beta_{5} \text { vministerial }_{\text {it }}+\beta_{6} \text { ele }_{\text {it }}+\beta_{7} x_{\text {it }}+\varepsilon_{t}
\end{aligned}
$$

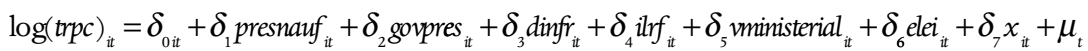

Onde:

$t_{r p c_{i t}}$ representa o montante de transferências correntes per capita em termos reais da União para o estado " $\mathrm{i}$ " na data " $\mathrm{t}$ "; ${ }^{15}$

presnauf $_{i t}$ representa a força política do presidente no estado "i" na data " $\mathrm{t}$ ", força definida da seguinte forma:

$$
\text { presnanf }_{i t}=\left(\frac{\text { Número de deputados e senadores do estado na coalizão do presidente }}{\text { Soma do número de deputados e senadores do estado nas casas do Congresso }}\right)_{i t}
$$

govpres ${ }_{i t}$ é uma variável binária que assume o valor "1" caso o partido político do presidente coincida com um dos partidos da coalizão que elegeu governador. Tal definição permite verificar se há ganho político no fato de haver convergência entre a legenda partidária do presidente e a base política do governador;

dinfr $r_{i t}$ é a soma das proporções, em relação ao total, dos gastos públicos em infraestrutura do estado " $\mathrm{i}$ " na data " $\mathrm{t}$ ";

ilf $_{i t}$ representa o índice de gastos com pessoal previsto nas Leis Camata I e II e na LRF do estado " $i$ " na data " $t$ " que, conforme argumentado nas seções anteriores, visam disciplinar os gastos públicos e, portanto, evitar transferências discricionárias;

ele $i_{i t}$ é uma variável binária que assume o valor "1" nos anos em que houve eleição presidencial;

rendaele $_{i t}$ é uma variável que representa a renda per capita do eleitorado de cada estado " $\mathrm{i}$ " em cada ano " $\mathrm{t}$ ", com dados deflacionados pelo IPCA;

vministerial ${ }_{i t}$ é o tempo ministerial de cada estado como proporção do tempo ministerial total em cada ano. Para cada estado "i" em cada ano " $t$ ", a partir da medida proposta por Amorim Neto e Borsani (2004), tal variável foi modificada e construída da seguinte forma:

$$
\text { vministerial }_{i t}=\frac{\text { n.ministros }_{i t} \times \text { n.dias no ministério }_{\text {it }}}{\text { total de ministérios }_{t} \times 365}
$$

$x_{i t}$ representa as demais variáveis de controle eventualmente utilizadas como instrumentos para as variáveis ilrf e vministerial, tais como as defasagens destas.

\footnotetext{
15 Outra "normalização”, como, por exemplo, a relação entre transferências e receitas correntes, foi testada. Porém, optou-se por seguir a literatura e a forma majoritária de representação, isto é, per capita. Não obstante, uma vez que o montante de transferências constitucionais deve ser praticamente constante, a possível utilização da rubrica "transferências voluntárias" seria redundante, dado que a análise é feita com base no nível e na taxa de variação da variável dependente. Caso contrário, a opção pelo montante global transferido é ainda mais adequada.
} 
Como é fácil observar, essa estrutura permite identificar os fatores que determinam não apenas o montante de recursos transferidos aos estados, mas ainda como eles influenciam a taxa de crescimento real do volume de recursos transferidos.

Todo o processo de estimação ${ }^{16}$ é conduzido por meio de um programa escrito em STATA. Após as especificações, três possíveis técnicas de estimação foram testadas: estimação com efeitos fixos, estimação com efeitos aleatórios e o método de variáveis instrumentais. Essa última foi utilizada devido à possível endogeneidade das variáveis ilrf e vministerial. Testes estatísticos-padrão foram utilizados, de modo a indicar a técnica de estimação mais robusta, a partir da qual será conduzido o processo de inferência. Todas essas técnicas têm seus resultados reportados nas Tabelas 1 e 2, de modo a atestar a consistência das estimações obtidas.

\section{Efeitos fixos ou efeitos aleatórios?}

Alguns autores, como Cossio (2000), justificam o uso de uma técnica de estimação baseada em efeitos fixos pelo simples fato de incorporar em sua amostra todos os possíveis cortes seccionais (em inglês, cross-sections), no caso, todos os estados do Brasil. Entretanto, o teste de Hausman é o critério mais consagrado para esse tipo de análise. Desse modo, serão apresentados os resultados das estimações por efeitos fixos e aleatórios e, após a realização do referido teste, será considerada ainda a possibilidade de endogeneidade das variáveis ilrf e vministerial.

Isso posto, o processo completo foi conduzido da seguinte forma: (i) a estimação dos modelos econométricos com efeitos fixos; (ii) a estimação dos modelos econométricos com efeitos aleatórios; (iii) a realização do teste de Hausman com o fito de validar uma das técnicas utilizadas em (i) e (ii); e (iv) a estimação dos modelos por meio da técnica de variáveis instrumentais, utilizando como instrumentos, além das exógenas, as duas defasagens do índice de gastos com pessoal previsto nas Leis Camata I e II e na LRF e a defasagem da variável que indica o tempo ministerial usado pelo estado.

\section{RESULTADOS}

As Tabelas 1 e 2 a seguir apresentam os resultados das estimações das equações apresentados, seguindo o processo descrito na seção anterior. Os valores nas referidas tabelas representam os coeficientes estimados das variáveis explicativas utilizadas nesta análise, com as respectivas estatísticas " $t$ " entre parênteses.

A Tabela 1 descreve os resultados das estimações para o modelo que tem como variável dependente o nível dos recursos reais per capita transferidos aos estados. Já a Tabela 2 apresenta os resultados relativos ao efeito das mesmas variáveis independentes sobre a evolução do montante dos recursos repassados a cada estado.

\footnotetext{
${ }^{16}$ Apenas por convenção, foi escrita uma rotina para estimação dos modelos de acordo com as diferentes técnicas utilizadas. Contudo, todas elas possuem comandos predefinidos no software STATA 10.0, o que torna desnecessário a apresentação de rotinas em um apêndice.
} 


\section{Resultados da especificação linear}

Os modelos 1, 2, 3, 4 e 5 demonstram como as variáveis explicativas selecionadas afetam o montante de recursos por habitante transferidos aos estados e, portanto, evidenciam o porquê de a população de alguns estados ser privilegiada em termos de recursos distribuídos pelo governo federal.

Tabela 1: Resultados das Estimações para Especificação Linear

\begin{tabular}{lccccc}
\hline Modelos & $(1)$ & $(2)$ & $(3)$ & $(4)$ & $(5)$ \\
Explicativas & $\operatorname{trpc}$ & $\operatorname{trpc}$ & $\operatorname{trpc}$ & $\operatorname{trpc}$ & $\operatorname{trpc}$ \\
\hline presnauf & 0.030 & 0.029 & 0.028 & 0.024 & 0.21 \\
& {$[2.03]^{*}$} & {$[1.97]^{*}$} & {$[1.81]+$} & {$[1.57]$} & {$[4.24]^{* *}$} \\
govpres & -0.033 & -0.033 & -0.024 & -0.024 & -0.02 \\
& {$[3.65]^{* *}$} & {$[3.73]^{* *}$} & {$[2.52]^{*}$} & {$[2.48]^{*}$} & {$[-0.61]$} \\
vministerial & 0.037 & -0.012 & 0.030 & & 0.91 \\
& {$[0.35]$} & {$[-0.11]$} & {$[0.29]$} & & {$[2.07]^{*}$} \\
elei & -0.002 & -0.003 & 0.008 & 0.009 & 0.00 \\
& {$[-0.27]$} & {$[-0.35]$} & {$[-1.12]$} & {$[1.15]$} & {$[-0.19]$} \\
ilrf1 & -0.104 & -0.098 & -0.201 & -0.215 & -0.37 \\
& {$[3.45]^{* *}$} & {$[3.24]^{* *}$} & {$[2.89]^{* *}$} & {$[3.07]^{* *}$} & {$[-4.35]^{* *}$} \\
dinfr & -0.342 & -0.341 & -0.258 & -0.232 & -0.41 \\
& {$[7.33]^{* *}$} & {$[7.25]^{* *}$} & {$[4.82]^{* *}$} & {$[4.27]^{* *}$} & {$[-2.66]^{* *}$} \\
rendaeleit & 0.292 & 0.298 & 0.285 & 0.283 & \\
& {$[24.15]^{* *}$} & {$[25.27]^{* *}$} & {$[22.07]^{* *}$} & {$[21.89]^{* *}$} & \\
vministerial-pós95 & & & & 0.215 & \\
& & & & {$[2.31]^{*}$} & \\
C & 0.069 & 0.059 & 0.125 & 0.13 & 0.07 \\
& {$[2.60]^{* *}$} & {$[1.58]$} & {$[2.51]^{*}$} & {$[2.62]^{* *}$} & {$[4.88]^{* *}$} \\
\hline Método & $\mathrm{EF}$ & $\mathrm{EA}$ & $\mathrm{VI}$ & $\mathrm{VI}$ & $\mathrm{VI}-\mathrm{Sudeste}$ \\
N. Obs. & 480 & 480 & 432 & 432 & 76 \\
Cross-Sections & 24 & 24 & 24 & 24 & 4 \\
$\mathrm{R}^{2}$ & 0.63 & & & & \\
\hline
\end{tabular}

Notas: 1) As estatísticas " $t$ " encontram-se entre colchetes.

2) EF: Estimação com Efeitos Fixos; VI: Estimação por Variáveis Instrumentais considerando a possível endogeneidade das variáveis ilrf e vministerial, para o Brasil e especificamente para a região Sudeste.

3) $(+)$ Significante a $10 \%$; $\left({ }^{*}\right)$ Significante a $5 \%$; $\left(^{*}\right)$ Significante a $1 \%$.

Os sinais dos coeficientes, sempre que significantes, se revelaram consistentes em todos os modelos, independentemente da técnica de estimação utilizada. Entretanto, o resultado ${ }^{17}$ do teste de Hausman, cuja não rejeição da hipótese nula pres-

${ }^{17}$ Os resultados obtidos para o teste de Hausman foram:

\begin{tabular}{|l|c|c|}
\hline Especificação & Estatística de Teste & P-valor \\
\hline Linear & 18,87 & 0,009 \\
\hline Log-Linear & 49,75 & 0,000 \\
\hline
\end{tabular}

Eles indicam a rejeição da hipótese nula a até $1 \%$. 
supõe a estimação de um modelo com efeitos aleatórios, permite concluir que a estimação por efeitos fixos seria a técnica mais robusta para a estimação dos modelos apresentados. Dessa forma, a inferência feita se baseará nos resultados da estimação por efeitos fixos e com o uso da técnica de variáveis instrumentais ${ }^{18}$ para cada variável de controle. A interpretação considerará o efeito sobre a variação das transferências por habitante em relação a uma média do período 1998-2004.

A força da coalizão do presidente no estado: a significância e o sinal da variável presnauf demonstram que o objetivo do presidente de formar e manter coalizões governativas se sobrepõe aos critérios de equidade na distribuição de recursos públicos. Note-se que o coeficiente dessa variável se mostrou consistente e positivo, conquanto perca um pouco em significância na estimação por variáveis instrumentais, permitindo inferir que quanto mais forte é a coalizão nacional do presidente em um estado, mais elevado é o montante de recursos por habitante transferido a este. Quantitativamente, o aumento de uma unidade nesta medida de força política implica algo em torno de $\mathrm{R} \$ 24$ a $\mathrm{R} \$ 30$ a mais, por habitante para o estado.

Coincidência partidária: note-se ainda que os coeficientes estimados para a variável govpres reforçam a afirmação segundo a qual a simples coincidência entre o partido do presidente e a coalizão eleitoral do governador não determina a alocação de recursos feitas pelo chefe do Executivo Federal, relação que se revelou insignificante estatisticamente no estudo de Arretche e Rodden (2004). De outro modo, e talvez para evitar favorecimentos explícitos, o fato de o governador ser da mesma legenda do presidente implica receber até $\mathrm{R} \$ 33$ a menos por habitante.

A Força ministerial dos estados: finalmente, no que toca à influência do tempo ministerial usado pelos estados sobre os recursos que lhes são transferidos, corrobora-se o argumento segundo o qual a instabilidade política do período pré-FHC compromete a significância da análise do efeito desta variável para a amostra como um todo. Constata-se que, para os 20 anos em tela, apenas na região Sudeste este efeito positivo é significativo. A importância da região Sudeste no cenário político nacional, medida pela percentagem de ministros oriundos dos estados que a integram, atesta a relevância desse resultado. Entretanto, considerando a interação entre o tempo ministerial e o período 1995-2004, constata-se novamente o efeito positivo e significante dessa variável que implica um adicional em torno de R\$21,50 por habitante.

Economia e gastos em infraestrutura: os resultados das estimativas para a variável dinfr reforçam o argumento apresentado, segundo o qual os gastos em infraestrutura poderiam comprometer a capacidade de o governo central atingir os seus objetivos políticos, devido ao fato de terem tais gastos impacto apenas no médio ou longo prazos. Os sinais negativos e significantes encontrados para os coeficientes estimados comprovam o argumento segundo o qual a redistribuição não é o objetivo central do governo federal no que se refere à alocação de recursos, pois, se assim fosse, se verificaria uma relação direta entre os estados que investem proporcionalmente mais em infraestrutura e o montante de recursos per

${ }^{18}$ Modelos 3, 4, 5, 8, 9 e 10. 
capita que lhes são destinados. Já as estimativas indicam entre R \$ 23,20 e R\$ 34,10 por habitante a menos para os estados que elevam os gastos nessa área.

Nível de renda: associando a verificação feita no parágrafo precedente aos sinais positivos e significantes dos coeficientes estimados para variável rendaeleit e à consequente relação direta entre o nível de renda do eleitorado e a alocação de recursos, é possível, então, corroborar a hipótese de Gibson, Calvo e Falleti (2004), segundo a qual o federalismo fiscal no Brasil é predominantemente realocativo. Os estados mais ricos recebem mais recursos, fato que contraria a ideia de distribuição.

$L R F$ : vale destacar o papel disciplinador das leis complementares que limitam os gastos com pessoal. Os sinais negativos e a significância obtida para os coeficientes estimados justificam uma mudança de padrão no crescimento dos gastos. A partir de 2000, a LRF passou a impor mais rigor no controle dos gastos públicos, o que significa que, principalmente nos períodos eleitorais, menos recursos são transferidos aos estados, reduzindo-se, portanto, a possibilidade do uso da máquina pública como instrumento de campanha eleitoral.

\section{Resultados da especificação log-linear}

Uma vez constatados o caráter realocativo do federalismo no Brasil, o efeito das variáveis políticas sobre os recursos per capita distribuídos aos estados e a importância de dispositivos disciplinadores dos gastos públicos, faz-se mister investigar as tendências relativas ao processo de distribuição dos recursos no Brasil. Ou seja, como evoluem esses recursos? Existiria a possibilidade de reversão do perfil acima identificado ou seria mais provável um agravamento desse padrão? A resposta a esses questionamentos pode ser inferida da Tabela 2 a seguir, em que são apresentadas as estimativas para a especificação log-linear. ${ }^{19}$

De maneira coerente com o caráter normativo do modelo de barganha, note-se novamente que o foco aqui não recai sobre a magnitude, mas sobre o sinal das estimativas obtidas. Um coeficiente negativo/positivo indica que a variável explicativa contribui para a/o diminuição/aumento do montante de recursos per capita em termos reais transferidos aos estados.

Tabela 2: Resultados das Estimações para Especificação Log-Linear

\begin{tabular}{lccccc}
\hline $\begin{array}{l}\text { Modelos } \\
\text { Explicativas }\end{array}$ & $\begin{array}{c}(6) \\
\text { logtrpc }\end{array}$ & $\begin{array}{c}(7) \\
\text { logtrpc }\end{array}$ & $\begin{array}{c}(8) \\
\text { logtrpc }\end{array}$ & $\begin{array}{c}(9) \\
\text { logtrpc }\end{array}$ & $\begin{array}{c}(10) \\
\text { logtrpc }\end{array}$ \\
\hline presnauf & 0.222 & 0.217 & 0.214 & 0.192 & 0.80 \\
& {$[4.01]^{*}$} & {$[3.90]^{* *}$} & {$[3.77]^{* *}$} & {$[3.39]^{* *}$} & {$[4.17]^{* *}$} \\
govpres & -0.178 & -0.177 & -0.152 & -0.148 & -0.09 \\
& {$[5.28]^{* *}$} & {$[5.26]^{* *}$} & {$[4.30]^{* *}$} & {$[4.26]^{* *}$} & {$[-0.78]$} \\
vministerial & -0.06 & -0.388 & -0.007 & & 2.93 \\
& {$[-0.15]$} & {$[-1.01]$} & {$[-0.02]$} & & {$[1.74]+$} \\
elei & -0.021 & -0.024 & 0.007 & 0.009 & -0.02 \\
& {$[-0.75]$} & {$[-0.85]$} & {$[-0.25]$} & {$[0.31]$} & {$[-0.29]$} \\
\hline
\end{tabular}

continua

19 A segunda equação do modelo econométrico apresentado na subseção 4.3. 


\begin{tabular}{|c|c|c|c|c|c|}
\hline \multirow[t]{2}{*}{ ilrf1 } & -0.72 & -0.685 & -1.128 & -1.216 & -1.42 \\
\hline & {$[6.32]^{* *}$} & {$[6.02]^{* *}$} & {$[4.37]^{* *}$} & {$[4.73]^{* *}$} & {$[-4.39]$} \\
\hline \multirow[t]{2}{*}{ dinfr } & -1.624 & -1.63 & -1.403 & -1.238 & -2.21 \\
\hline & {$[9.21]^{* *}$} & {$[9.21]^{* *}$} & {$[7.06]^{* *}$} & {$[6.19]^{* *}$} & {$[-3.68]^{* *}$} \\
\hline \multirow[t]{2}{*}{ rendaeleit } & 0.626 & 0.648 & 0.599 & 0.586 & \\
\hline & {$[13.71]^{* *}$} & {$[15.38]^{* *}$} & {$[12.50]^{* *}$} & {$[12.35]^{* *}$} & \\
\hline \multirow[t]{2}{*}{ vministerial-pós95 } & & & & 1.413 & \\
\hline & & & & {$[4.14]^{* *}$} & \\
\hline \multirow[t]{2}{*}{ C } & -1.521 & -1.556 & -1.265 & -1.237 & -1.02 \\
\hline & {$[15.19]^{* *}$} & {$[13.77]^{* *}$} & {$[6.85]^{* *}$} & {$[6.77]^{* *}$} & {$[-3.82]^{* *}$} \\
\hline Método & $E F$ & EA & $\mathrm{VI}$ & $\mathrm{VI}$ & VI-Sudeste \\
\hline N. Obs. & 480 & 480 & 432 & 432 & 76 \\
\hline Cross Sections & 24 & 24 & 24 & 24 & 4 \\
\hline $\mathrm{R}^{2}$ & 0.51 & & & & \\
\hline
\end{tabular}

Notas: 1) As estatísticas " $t$ " encontram-se entre colchetes.

2) EF: Estimação com Efeitos Fixos; VI: Estimação por Variáveis Instrumentais considerando a possível endogeneidade das variáveis ilrf e vministerial, para o Brasil e especificamente para a região Sudeste.

3) $(+)$ Significante a $10 \%$; (*) Significante a $5 \%$; $\left(^{* *}\right)$ Significante a $1 \%$.

Verifica-se que as perspectivas para a reversão do caráter realocativo do federalismo no Brasil não são as melhores, uma vez que os resultados obtidos são basicamente os mesmos para todas as variáveis explicativas. Sempre que significantes, os sinais obtidos para os coeficientes estimados permanecem os mesmos da especificação linear, seja para as variáveis econômicas, seja para as políticas. Dito de outra forma, quanto mais forte a coalizão do presidente nos estados e quanto mais elevado o nível de renda do eleitorado, maior a taxa de crescimento dos recursos per capita recebidos da União, relação que se confirma para o tempo ministerial usado pelos estados no período 1995-2004 ou apenas pelos estados do Sudeste. Por outro lado, para os estados que gastam proporcionalmente mais visando ao crescimento de longo prazo, as perspectivas em termos de fluxo de transferências advindas da União não são positivas.

Ainda que se reconheça a importância dos dispositivos que propõem maior austeridade no gasto público, é inevitável a conclusão de que, no curto e médio prazos, o cenário mais provável é o de manutenção ou mesmo de agravamento das desigualdades na distribuição dos recursos federais no Brasil.

\section{CONCLUSÃO}

Considerando a importância de uma distribuição equitativa dos recursos públicos para o desenvolvimento de países como o Brasil, o presente artigo almejou ampliar as propostas anteriores de Cossio (2000) e Arretche e Rodden (2004), no sentido de responder ao questionamento de Lasswell (1936), muito bem lembrado por esses dois últimos autores: quem ganha o quê, quando e por quê?

Com base em evidências que atestam o caráter realocativo do federalismo fiscal no Brasil e no modelo de Rao e Singh (2000), o qual vê o federalismo como uma barganha constitucional, empreendeu-se aqui uma análise empírica com o propósito de avaliar como o país lida com o "cobertor curto" que se observa entre, 
por um lado, a promoção do desenvolvimento subnacional, e, por outro, a consecução de objetivos políticos do governo central.

Variáveis políticas e econômicas foram elaboradas tanto para investigar os fatores que determinam as decisões de alocação dos recursos federais no Brasil, como para verificar a relevância de dispositivos disciplinadores, como a LRF, em tais decisões. As variáveis políticas que se revelaram significantes foram a força da coalizão do presidente nos estados (presnauf) e o tempo de participação ministerial anual destes (vministerial). Todavia, os estados cujo governador pertence à coalizão do presidente recebem menos recursos. Embora contraditória, essa verificação pode indicar uma prática cujo fim é evitar denúncias de favorecimentos políticos explícitos.

Ao fim e ao cabo, a consecução dos objetivos políticos prepondera sobre os critérios de equidade: níveis mais elevados de transferência per capita estão associados à composição partidário-estadual das coalizões governativas (presnauf), enquanto maiores investimentos em infraestrutura e desenvolvimento (dinfr) estão relacionados a menor montante de recursos por habitante transferido a cada estado. Os testes aqui realizados permitem ainda diagnosticar uma tendência à manutenção das desigualdades inter-regionais no Brasil, uma vez que tanto o nível como a evolução dos recursos transferidos aos estados parece ser definida muito mais pela força política destes do que por critérios de redução das desigualdades inter-regionais e de atendimento das necessidades das populações locais. De maneira complementar, os resultados das estimações estatísticas reportadas neste artigo reafirmam o importante papel desempenhado pelas leis que limitam os gastos com o funcionalismo no combate ao uso da máquina administrativa para fins eleitorais.

Por último, cumpre ressalvar que a constatação do primado dos objetivos políticos do presidente não deve ser lida como uma denúncia generalizada contra a política. Os autores deste artigo estão plenamente cientes de que, em um regime democrático, não se executam políticas, por melhores que sejam, sem se fazer política, isto é, sem se conseguir o apoio majoritário de eleitores e partidos e sem se fazer concessões pragmáticas e programáticas. Um presidente que deseje transferir recursos da União para os estados com o objetivo de reduzir as desigualdades inter-regionais também tem de contar com sólido respaldo político para sustentar tal decisão ao longo do seu mandato. Porém, feita a ressalva, é legítimo afirmar que, de um ponto de vista normativo, as transferências intergovernamentais no Brasil são politizadas demais. A política deve estar sempre presente nas decisões de gastos públicos, mas quiçá seja chegada a hora de se reforçarem os critérios de equidade na distribuição dos recursos da União para os governos subnacionais.

\section{REFERÊNCIAS BIBLIOGRÁFICAS}

Abranches, Sérgio H. H. (1988) "Presidencialismo de coalizão: o dilema institucional brasileiro". Dados 31: 5-38.

Abrucio, Fernando L. (1998) Os Barões da Federação. São Paulo: Hucitec. ; Costa, Valeriano Mendes Ferreira. (1999) Reforma do Estado e o Contexto Federativo Brasileiro. São Paulo: Fundação Konrad Adenauer. 
Amorim Neto, Octavio. (2000) “Gabinetes presidenciais, ciclos eleitorais e disciplina legislativa no Brasil.” Dados 43: 479-519.

. (2007) "Algumas consequencias políticas de Lula: novos padrões de formação e recrutamento ministerial, controle de agenda e produção legislativa”. In: Jairo Nicolau e Timothy J. Power (Org.), Instituições Representativas no Brasil: Balanço e Reformas. Belo Horizonte: Editora UFMG.

; Borsani, Hugo. (2004) "Presidents and cabinets: the political determinants of fiscal behavior in Latin America”. Studies in Comparative International Development 39, p. 3-27.

Arretche, Marta. (2005) “Quem gasta e quem taxa: a barganha federativa na federação brasileira.” Revista de Sociologia Política 24, p. 69-85.

. (2009). "Continuidades e descontinuidades da federação brasileira: de como 1988 facilitou 1995”. Dados 52, p. 377-423.

. (2010). "Federalismo e igualdade territorial: uma contradição em termos?" Dados 53, p. 587 $-620$.

Arretche, Marta e Rodden, J. (2004) "Política distributiva na federação: estratégias eleitorais, barganhas legislativas e coalizões de governo". Dados 47, p. 549-576.

Berry, William e Lowery, David. (1987) "Explaining the size of the public sector: responsive and excessive government interpretations." Journal of Politics 49, p. 401-40.

Brasil. Secretaria do Tesouro Nacional. (1996) Execução Orçamentária dos Estados e Municípios das Capitais, 1986-1995. Brasília.

. (2011) "O que você precisa saber sobre as transferências constitucionais relativas aos fundos de participação dos estados e dos municípios.” Brasília, http://www.tesouro.fazenda.gov.br/servicos/ download/cartFPEeFPM.pdf, acessado em 19/10/2012.

Carey, John M. e Gina Y. Reinhardt. (2003) "Impacto das instituições estaduais na unidade das coalizões parlamentares no Brasil.” Dados 46, p. 773-804.

Cheibub, José Antonio; Figueiredo, Argelina e Limongi, Fernando. (2009) "Political parties and governors as determinants of legislative behavior in Brazil's chamber of deputies." Latin American Politics and Society 51, p. 1-30.

Cossio, Fernando A. B. (2000) "O comportamento fiscal dos estados brasileiros e seus determinantes políticos”. In: Anais do XXVIII Encontro da ANPEC, CD-ROM, 22p, Campinas, São Paulo.

Falleti, Tulia G. (2005) "A sequential theory of decentralization: Latin American cases in comparative perspective”. American Political Science Review 99, p. 327-346.

Figueiredo, Argelina C. (2008) "Government coalitions in Brazilian Democracy." Brazilian Political Science Review 1, p. 182-216.

Gibson, Edward L.; Calvo, Ernesto F. e Falleti, Tulia G. (2004) "Reallocative federalism: overrepresentation and public spending in the western hemisphere.” In: Edward Gibson (Orgs.), Federalism: Latin America in Comparative Perspective, Baltimore: Johns Hopkins University Press.

Lasswell, Harold. (1936) Politics: Who Gets What, When and How? New York: P. Smith.

Power, Timothy J. (2010) "Optimism, pessimism, and coalitional presidentialism: Debating the institutional design of Brazilian democracy." Bulletin of Latin American Research 29, p. 18-33.

Rao, Marapalli G. e Singh, Nirvikar (2000) "The political economy of center-state fiscal transfers in India”. Working Paper presented at Columbia University-World Bank Conference on Institutional Elements of Tax Design and Reform.

Souza, Celina (2003) "Federalismo e conflitos distributivos: disputa dos estados por recursos orçamentários federais." Dados 46, p. 345-384.

Ter-Minassian, Teresa. (1999) "Descentralização e gestão macroeconômica”. In: OECD-ESAF: Conferência Internacional em Descentralização, Relações Fiscais e Intergovernamentais e Governança Macroeconômica, Brasilia, DF. 